\title{
ATP-Driven Exchange of Histone H2AZ Variant Catalyzed by SWR1 Chromatin Remodeling Complex
}

Gaku Mizuguchi et al.

Science 303, 343 (2004);

DOI: $10.1126 /$ science.1090701

This copy is for your personal, non-commercial use only.

If you wish to distribute this article to others, you can order high-quality copies for your colleagues, clients, or customers by clicking here.

Permission to republish or repurpose articles or portions of articles can be obtained by following the guidelines here.

The following resources related to this article are available online at www.sciencemag.org (this information is current as of May 20, 2014 ):

Updated information and services, including high-resolution figures, can be found in the online version of this article at:

http://www.sciencemag.org/content/303/5656/343.full.html

Supporting Online Material can be found at:

http://www.sciencemag.org/content/suppl/2004/01/15/1090701.DC1.html

A list of selected additional articles on the Science Web sites related to this article can be found at:

http://www.sciencemag.org/content/303/5656/343.full.html\#related

This article cites 33 articles, 11 of which can be accessed free:

http://www.sciencemag.org/content/303/5656/343.full.html\#ref-list-1

This article has been cited by 394 article(s) on the ISI Web of Science

This article has been cited by 100 articles hosted by HighWire Press; see:

http://www.sciencemag.org/content/303/5656/343.full.html\#related-urls

This article appears in the following subject collections:

Molecular Biology

http://www.sciencemag.org/cgi/collection/molec_biol 
expected for a high, Newtonian viscosity (54).

Of course, our images only provide a snapshot of the current mantle, and we are unable to infer the rise velocity of the plumes. Because of this, we are unable to place a firm constraint on the heat flux carried by the plumes; however, an order-of-magnitude calculation indicates that the observed heat flux of about 44 TW at Earth's surface imposes a limit on the rise velocity of the plumes, which is probably below $10 \mathrm{~cm} /$ year (55). This loose constraint reinforces our conclusion that convection in the lower mantle is slow, and indicates that the role of plumes in transporting heat from the core to the surface of the Earth is larger than previously suggested (1).

Another surprising observation is the lack of correlation between the maximum depth of a plume image and the associated ${ }^{3} \mathrm{He} /{ }^{4} \mathrm{He}$ anomaly. Of the ocean islands with high values of ${ }^{3} \mathrm{He} /{ }^{4} \mathrm{He}$ (3), Easter, Hawaii, Kerguelen, Samoa, and Tahiti are well-resolved deep plumes (Table 1). Afar, Cape Verde, Caroline, Reunion, and Jean Fernandez are potential $D^{\prime \prime}$ plumes and also have correspondingly high ${ }^{3} \mathrm{He} /{ }^{4} \mathrm{He}$. But other plumes for which a deep origin can be decisively ruled out (Galapagos, Iceland) have high ${ }^{3} \mathrm{He} /{ }^{4} \mathrm{He}$. Conversely, St. Helena and Canary Islands have a low ${ }^{3} \mathrm{He} /{ }^{4} \mathrm{He}$ ratio but have anomalous velocities that extend deeply into the mantle.

The maximum velocity anomaly of the observed plumes in the lower mantle is reduced by a factor of about 3 with respect to the value found in the upper mantle (which is often in excess of $-1.5 \%$ ). Even though the magnitude of each plume anomaly is affected by the resolution, this diminution of $\delta v_{P} / v_{P}$ with depth is in accordance with predictions of $d v_{P} / d T$ (42).

\section{References and Notes}

1. N. H. Sleep, J. Geophys. Res. 95, 6715 (1990).

2. G. F. Davies, J. Geophys. Res. 93, 10467 (1988).

3. V. Courtillot, A. Davaille, J. Besse, J. Stock, Earth Planet. Sci. Lett. 205, 295 (2003)

4. J. T. Wilson, Can. J. Phys. 41, 863 (1963).

5. J. T. Wilson, Philos. Trans. R. Soc. London 258A (1965).

6. W. J. Morgan, Nature 230, 42 (1971)

7. W. J. Morgan, Geol. Soc. Am. Mem. 132, 7 (1972).

8. M. A. Richards, R. A. Duncan, V. E. Courtillot, Science 246, 103 (1989).

9. V. Courtillot, C. Jaupart, I. Manighetti, P. Tapponier, J. Besse, Earth Planet. Sci. Lett. 166, 177 (1999).

10. I. O. Norton, The History and Dynamics of Global Plate Motions (Geophysical Monograph 121, American Geophysical Union, Washington, DC, 2000), Pp. 339-357.

11. A. Davaille, Nature 402, 756 (1999).

12. A. Davaille, F. Girard, M. L. Bars, Earth Planet. Sci. Lett. 203, 621 (2002).

13. H.-P. Bunge, M. A. Richards, J. R. Baumgardner, J. Geophys. Res. 102, 11991 (1997).

14. S. Zhong, M. T. Zuber, L. Moresi, M. Gurnis, J. Geophys. Res. 105, 11063 (2000).

15. L. Cserepes, D. A. Yuen, Earth Planet. Sci. Lett. 183, 61 (2000).

16. D. L. Anderson, The Core-Mantle Boundary Region (American Geophysical Union, Washington DC 1998), pp. 255-271.

17. D. L. Anderson, Geophys. Res. Lett. 27, 3623 (2000).
18. G. R. Foulger, J. H. Natland, Science 300, 921 (2003)

19. F. A. Dahlen, S.-H. Hung, G. Nolet, Geophys. J. Int. 141, 157 (2000).

20. S.-H. Hung, F. A. Dahlen, G. Nolet, Geophys. J. Int 141, 175 (2000).

21. Y. A. Kravtsov, Y. I. Orlov, Geometrical Optics of Inhomogeneous Media (Springer-Verlag, New York, 1990).

22. G. Nolet, F. A. Dahlen, J. Geophys. Res. 105, 19043 (2000).

23. S.-H. Hung, F. A. Dahlen, G. Nolet, Geophys. J. Int 146, 289 (2001).

24. R. Montelli, G. Nolet, G. Masters, F. A. Dahlen, S.-H Hung, Geophys. J. Int., in press.

25. H.-C. Nataf, J. VanDecar, Nature 364, 115 (1993).

26. The dominant periods of travel times in the bulletins are poorly documented and vary among stations, but are commonly obtained from instruments that are sensitive to a narrow band of frequencies around 1 $\mathrm{Hz}$.

27. H. Bolton, G. Masters, J. Geophys. Res. 106, 13527 (2001).

28. H. Bolton, thesis, University of California, San Diego (1996).

29. See supporting data on Science Online.

30. E. R. Engdahl, R. D. van der Hilst, R. Buland, Bull. Seismol. Soc. Am. 88, 722 (1998).

31. A. Morelli, A. M. Dziewonski, in Seismic Tomography, G. Nolet, Ed. (Reidel, Dordrecht, Netherlands, 1987) pp. 251-274.

32. J. Ritsema, S. Ni, D. V. Helmberger, H. P. Crotwell, Geophys. Res. Lett. 25, 4245 (1998).

33. S. Ni, E. Tan, M. Gurnis, D. Helmberger, Science 296 1850 (2002)

34. R. D. van der Hilst, S. Widiyantoro, E. R. Engdahl, Nature 386, 578 (1997).

35. S. P. Grand, R. D. van der Hilst, S. Widiyantoro, GSA Today 7, 1 (1997).

36. S. P. Grand, J. Geophys. Res. 99, 11591 (1994).

37. H. Bijwaard, W. Spakman, E. R. Engdahl, J. Geophys. Res. 103, 30055 (1998)

38. R. Van der Voo, W. Spakman, H. Bijwaard, Nature 397, 246 (1999)

39. Y. J. Gu, A. M. Dziewonski, W. Su, G. Ekström, J. Geophys. Res. 106, 11169 (2001)

40. J. O'Keefe, A. Eckels, R. Squires, Science 129, 565 (1959).
41. H. Bijwaard, W. Spakman, Earth Planet. Sci. Lett. 166, 121 (1999).

42. S.-I. Karato, Geophys. Res. Lett. 20, 1623 (1993)

43. N. H. Sleep, Geochem. Geophys. Geosyst. 3, 10.1029/ $2001 G C 00290$ (2002).

44. W. J. Morgan, personal communication.

45. A. Wegener, The Origin of Continents and Oceans (Methuen, London, 1924).

46. R. D. van der Hilst, H. Kárason, Science 283, 1885 (1999).

47. W.-J. Su, A. M. Dziewonski, Phys. Earth Planet. Inter. 100, 135 (1997)

48. D. L. Anderson, Science 293, 2016 (2001).

49. J. E. Vidale, G. Schubert, Geophys. Res. Lett. 28, 859 (2001).

50. D. W. Vasco, L. R. Johnson, O. Marques, J. Geophys. Res. 108, 2022 (2003)

51. L. H. Kellogg, B. H. Hager, R. D. van der Hilst, Science 283, 1881 (1999).

52. P. J. Tackley, Science 288, 2002 (2000).

53. P. Wu, Geophys. J. Int. 139, 691 (1999).

54. P. van Keken, Earth Planet. Sci. Lett. 148, 1 (1997).

55. For example, if we integrate $\Delta T$ at $800 \mathrm{~km}$ depth over the total area for which $\delta v_{p} / v_{p}<-0.5 \%(\Delta T=100$ K) using $d \ln V_{p} / d T=-0.51 \times 10^{-4} \mathrm{~K}^{-1}$, a heat capacity $c_{p}=1270 \mathrm{~J} \mathrm{~kg}^{-1} \mathrm{~K}^{-1}$, a density $\rho=4450$ $\mathrm{kg} \mathrm{m}^{-3}$, and a rise velocity of $1 \mathrm{~cm} /$ year, we obtain an advective heat flux of 9.8 TW. The estimate scales linearly with the assumed rise velocity. Smoothing does not influence the flux itself, but may underestimate the area confined by the $-0.5 \%$ isosurface, so this is a conservative estimate that could easily be larger. Imposing a different limit (e.g., $0.7 \%$ or $140 \mathrm{~K}$ ) brings the flux down to $3.1 \mathrm{TW}$ for $1 \mathrm{~cm} /$ year.

56. We thank J. Morgan for numerous discussions and helpful suggestions. Supported by NSF grants EAR9814570 and EAR-0105387.

Supporting Online Material

www.sciencemag.org/cgi/content/full/1092485/DC1

SOM Text

Figs. S1 to S21

References

10 October 2003; accepted 18 November 2003 Published online 4 December 2003,

10.1126/science. 1092485

Include this information when citing this paper.

\title{
ATP-Driven Exchange of Histone H2AZ Variant Catalyzed by SWR1 Chromatin Remodeling Complex
}

\author{
Gaku Mizuguchi,* Xuetong Shen, ${ }^{*} \dagger$ Joe Landry,* Wei-Hua Wu, \\ Subhojit Sen, $\uparrow$ Carl Wu $\S$
}

The conserved histone variant $\mathrm{H} 2 \mathrm{AZ}$ has an important role in the regulation of gene expression and the establishment of a buffer to the spread of silent heterochromatin. How histone variants such as $\mathrm{H} 2 \mathrm{AZ}$ are incorporated into nucleosomes has been obscure. We have found that Swr1, a Swi2/Snf2-related adenosine triphosphatase, is the catalytic core of a multisubunit, histone-variant exchanger that efficiently replaces conventional histone $\mathrm{H} 2 \mathrm{~A}$ with histone $\mathrm{H} 2 \mathrm{AZ}$ in nucleosome arrays. Swr 1 is required for the deposition of histone H2AZ at specific chromosome locations in vivo, and Swr1 and H2AZ commonly regulate a subset of yeast genes. These findings define a previously unknown role for the adenosine triphosphate-dependent chromatin remodeling machinery.

The condensation of eukaryotic DNA in arrays of nucleosomes has a profound effect on gene function. To counteract constraints imposed by nucleosome structure, cells deploy two major classes of multiprotein enzymes, which covalently modify the nucleosome core histones or catalyze nucleosome mobility in an adenosine triphosphate (ATP)-dependent fashion (1-5). Much of our current understanding of these processes is derived 


\section{RESEARCHARTICLES}

from analyses of nucleosomal histones that represent the major histone species within cells. However, the existence of minor histone variants, encoded by distinct, nonallelic genes, has long been recognized (6). Recent studies have revealed that variants of histone $\mathrm{H} 2 \mathrm{~A}$ and histone $\mathrm{H} 3$ play important roles not only in gene expression but also in the repair of DNA breaks and the assembly of chromosome centromeres (7-9). These advances establish a third mechanism of chromatin reconfiguration, raising fundamental questions about the stability of nucleosomes in nonreplicative phases of the cell cycle and the cellular machinery responsible for incorporating histone variants into nucleosomes.

The histone H2A.F/Z (H2AZ) variant is a functionally distinct, highly conserved histone subgroup that likely represents a separate evolutionary lineage of histone $\mathrm{H} 2 \mathrm{~A}$ proteins $(7,10)$. Histone $\mathrm{H} 2 \mathrm{AZ}$ replaces the major histone $\mathrm{H} 2 \mathrm{~A}$ in a fraction of the nucleosomes isolated from chromatin (11) and reconstitutes a similar though nonidentical structure to the canonical nucleosome (12). There is growing evidence that the incorporation of $\mathrm{H} 2 \mathrm{AZ}$ has an important influence on gene expression. (7). Moreover, $\mathrm{H} 2 \mathrm{AZ}$ in transcriptionally active domains near yeast

Laboratory of Molecular Cell Biology, National Cancer Institute, National Institutes of Health, Building 37, Room 6068, Bethesda, MD 20892-4255, USA.

*These authors contributed equally to this work. †Present address: Department of Carcinogenesis, MD Anderson Cancer Center, Science Park Research Division, Smithville, TX 78957, USA.

tThese authors contributed equally to this work. $\S$ To whom correspondence should be addressed. Email: carlwu@helix.nih.gov

Fig. 1. SWR1 complex is associated with histone variant $\mathrm{Htz} 1$. (A) SDS-PAGE and Coomassie Blue staining of proteins associated with native Swr1-Flag and Ino80Flag. Gel bands containing single or multiple proteins (brackets) were analyzed by peptide sequencing. Solid squares mark subunits shared between SWR1 and INO80 complexes. (B) Thin-layer chromatography showing nucleosome (nuc)-stimulated ATPase activity of the SWR1 complex. (C) SDS-PAGE

A

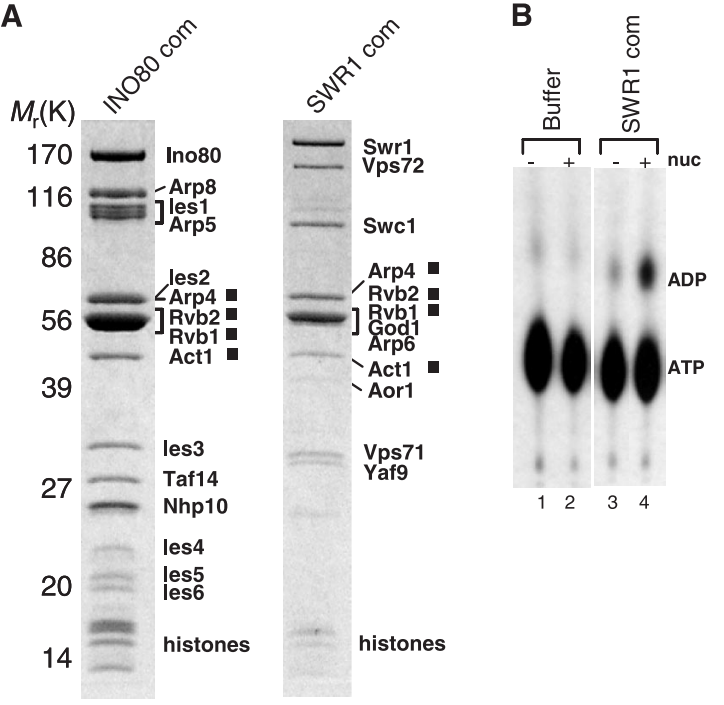

telomeres and flanking the HMR mating-type locus functions as a buffer to gene silencing caused by the spread of heterochromatin proteins (13). Here, we show that Saccharomyces cerevisiae Swr1, an uncharacterized member of the Swi2/Snf2 family of chromatin remodeling adenosine triphosphatases (ATPases) $(2,4,5,14)$, is contained in a multicomponent protein complex that catalyzes H2AZ-specific histone exchange.

A multicomponent SWR1 complex containing H2AZ (Htz1). In budding yeast, the paralogous genes SWRI and INO80 are distinguished from other members of the $S W I 2 / S N F 2$ family by an insertion that splits the conserved ATPase domain into two segments. In contrast to Ino80 $(15,16)$, little is known about Swr1 (17). To enable purification of native Swr1, we engineered a triple Flag epitope tag at its $\mathrm{C}$ terminus (18) and verified the function of Swr1-Flag in vivo (19). Immunopurification from whole-yeast extracts revealed over 12 proteins associating with Swr1-Flag (Fig. 1A). This assembly, named the SWR1 complex, sediments as a peak during glycerol gradient centrifugation and exhibits nucleosome-stimulated ATPase activity (Fig. 1B). We identified components of the SWR1 complex by peptide microsequencing with the use of mass spectrometry. Several subunits-Act1, Arp4, Rvb1, and Rvb2-are common to the INO80 complex (15) and other chromatin remodeling complexes (14) (Fig. 1A). Arp6 is an actin-related protein (20), Yaf9 is the yeast counterpart of the human leukemogenic protein AF9 (21), and the remaining SWR1 subunits-Vps72, Vps71, Swc1,
Aor1, and God1-are uncharacterized database entries (17).

Several small polypeptides that copurified with the SWR1 and INO80 complexes were identified as histones (Fig. 1A). Although the association of histones with chromatin remodeling complexes could be due to nonspecific binding of chromatin, the persistence of histone binding upon nuclease digestion suggested otherwise (19). Among the histones copurifying with the SWR1 complex, a substantial number of tryptic peptides are derived from histone $\mathrm{Htz1}$, the $\mathrm{H} 2 \mathrm{AZ}$ variant in yeast (table S1).

Purified Htz1 associates with SWR1 complex. To confirm the physical interaction between yeast Htzl and the SWR1 complex, we immunopurified native Htz1-Flag from whole yeast extracts. We found that Htz1 copurified with its partner histone H2B and many other polypeptides, including all components of the SWR1 complex (Fig. 1C). Glycerol gradient centrifugation separated the free Htz1-H2B dimer (fraction 5) from two additional assemblies: the SWR1 complex (fraction 22) and a complex we named NAP-Z, containing the nucleosome assembly protein Nap1 (22) and other polypeptides (fraction 12) (Fig. 1C). The bulk of soluble Htz1 is distributed between free Htz1-H2B dimers and Nap1-associated Htz1-H2B dimers. The SWR1 complex contains only a minor portion of the soluble Htz1-H2B dimer population.

Swr1 and Htz1 functions overlap in vivo. To determine the biological relevance of the interaction between Htzl and the SWR1 complex, we analyzed the growth phenotypes of mutants (23). The swrl null or

and silver staining of proteins associated with native Htz1-Flag (HTZ1 coms). Gel bands were identified as above. Unassigned polypeptides include Cdc48, Ctr9, Mec1, Ksp1, Kap114, Bdf1, Rtf1, Yku80, Leo1, Aor1, Nbp2, Rpa34, Yer030w, and Ymr247c. HTZ1 coms were separated by glycerol gradient centrifugation, and fractions were analyzed by SDS-PAGE. Proteins were identified by comparison with

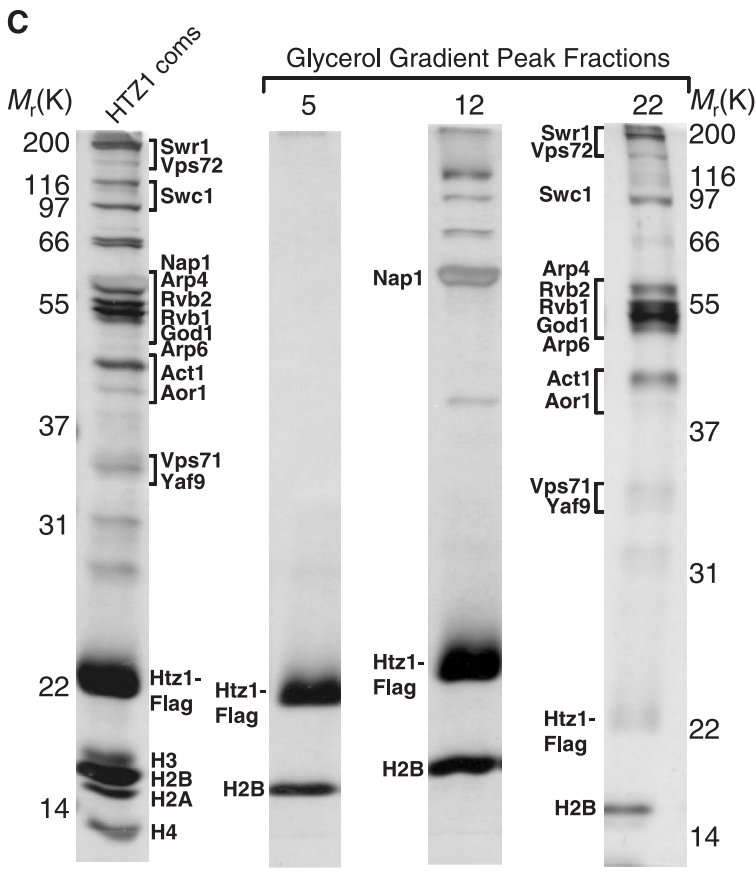
the input. 
catalytic site mutant is viable and sensitive to caffeine and the alkylating agent methyl methanesulfonate (MMS) and weakly sensitive to ultraviolet (UV) irradiation (Fig. 2A). The htzl mutant is also viable, sensitive to caffeine and MMS (24), and moderately sensitive to UV, implicating a role for both proteins in DNA damage repair and other metabolic activities (23). However, the $h t z 1$ mutant is more sensitive than swrl to diminished deoxynucleotide triphosphate pools caused by the ribonucleotide reductase inhibitor hydroxyurea (HU) (Fig. 2A). The swrl phenotypes were rescued by the wild-type gene but not by a mutant carrying a Lys $^{727} \rightarrow \mathrm{Gly}^{727}$ (K727G) substitution in the ATP-binding motif of Swr1, indicating that ATP-use is crucial for its in vivo function (Fig. 2A).

We also examined genome-wide transcription profiles for swrl and htzl mutants (Fig. 2B). Complementary DNA hybridization to yeast whole-genome microarrays revealed that 71 out of 162 Swr1-activated genes are also activated by Htzl (44\% overlap). Of 77 genes repressed by Swr1,
29 are also repressed by Htz1 (38\% overlap). The incompleteness of the overlaps suggests a degree of functional independence for the two genes, or it may reflect an inherent limitation of microarray analyses. By contrast, 48 out of 446 Ino80-activated genes are also activated by Htz1 (11\% overlap), and 72 out of 779 Ino80-repressed genes are also repressed by Htz1 (9\% overlap). The Swr1-activated, but not Ino80activated, genes are highly represented near yeast telomeres, consistent with the chromosomal locations of Htz1-activated genes (13) (Fig. 2C). We found no preferential location of Htz1- or Swr1-repressed genes at yeast telomeres (fig. S1).

Chromatin binding of $\mathrm{Htz} 1$ in vivo requires Swr1. The physical and functional connections between Swr1 and Htzl suggested that the SWR1 complex might facilitate the assembly or remodeling of variant nucleosomes containing Htz1, leading to changes in transcription of targeted genes. Accordingly, we compared the in vivo binding of Htzl at various chromosomal locations in wild-type and swrl mutant cells with the use
A
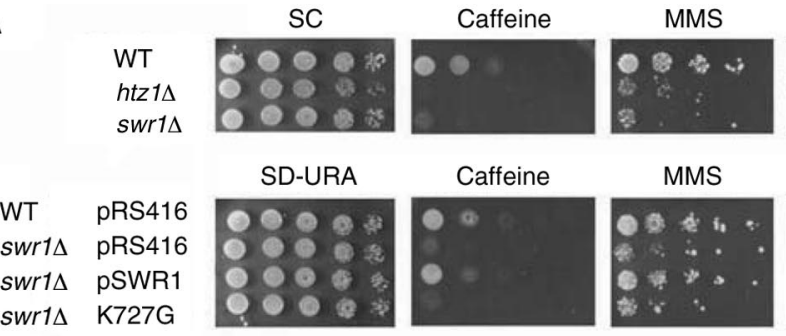
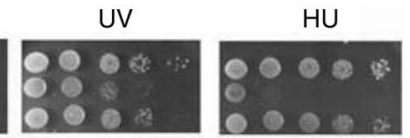

HU

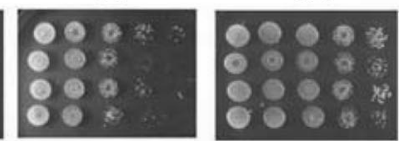

B
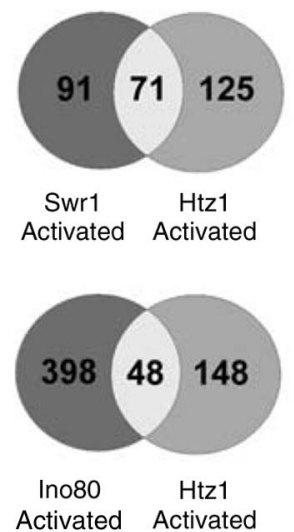
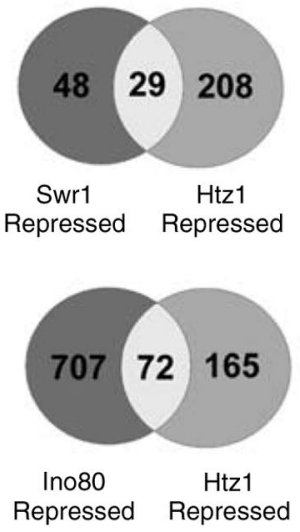

C
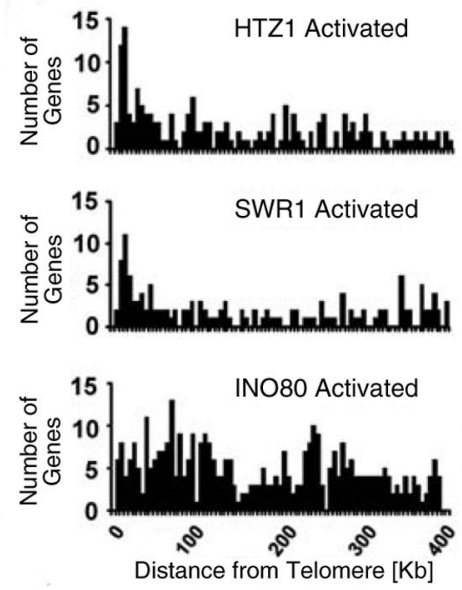

Fig. 2. SWR1 and HTZ1 share common functions in vivo. (A) Saturated cultures (1:10 serial dilutions) of the indicated strains with or without the PRS416 episomal vector, a vector containing either Swr1 or the K727G mutant, were grown in synthetic complete media (SC) (upper), or synthetic dropout media (SD-Ura) (lower), supplemented with $20 \mathrm{mM}$ caffeine, $0.25 \% \mathrm{MMS}$, and

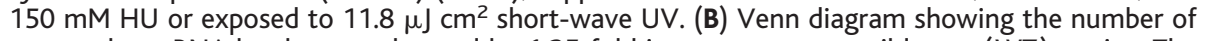
genes whose RNA levels were changed by 1.25 -fold in mutant versus wild-type (WT) strains. The overlap signifies commonly misregulated genes. Microarray data (44) were analyzed by $t$ tests and Benjamini and Hochberg multiple testing corrections at $95 \%$ confidence levels. $P$ values were as follows: $P=0$ (44\% overlap), $P=10^{-19}$ (38\% overlap), $P=10^{-12}$ (11\% overlap), and $P=10^{-11}$ ( $9 \%$ overlap). Northern analysis of representative genes are in table S3. Overlap between data sets using 1.5- and 2-fold cutoffs are given in fig. S4. (C) Diagram showing the number of Htz1-, Swr1-, or Ino80-activated genes ( $y$ axis) as a function of distance in 5-kb units from the telomere ( $x$ axis).

of formaldehyde cross-linking and chromatin immunoprecipitation (ChIP). Htzl is known to bind preferentially near telomeres and at regions flanking the silent mating type locus, where it antagonizes the effects of gene silencing by heterochromatin (13). At $\sim 3 \mathrm{~kb}$ from the telomere, binding of Htzl at the RDS1 promoter was lost in the swrl null or catalytic site mutant (Fig. 3, A and B, primer pair CR2). This cannot be attributed to a failure to express Htzl in the swrl mutant (Fig. 3A, inset). Loss of Htzl binding in $s w r 1$ also occurs at the $A D E 17$ promoter, $\sim 415 \mathrm{~kb}$ from the telomere (Fig. 3C, primer pair A3). Likewise, a loss of Htz1 binding is observed at CAR2 and LSM3 coding regions, $\sim 65 \mathrm{~kb}$ from the telomere (Fig. 3D, primer pairs C3 and C4).

SWR1 complex catalyzes replacement of H2A with Htz1 in vitro. How might Swr1 be used for the incorporation of Htz1 in chromatin? We proposed that the ATPdriven disruption of conventional nucleosomes by the SWR1 complex leads to displacement of histone H2A (probably as the $\mathrm{H} 2 \mathrm{~A}-\mathrm{H} 2 \mathrm{~B}$ dimer) and replacement with Htz1 (Htz1-H2B) in a histone dimer exchange reaction. Accordingly, we prepared immobilized nucleosome arrays with the use of DNA bound to magnetic beads and a recombinant yeast nucleosome assembly system $(25,26)$. Incubation with the SWR1 complex, a source of Htz1-H2B dimers, and ATP revealed a striking transfer of Htz1-Flag to immobilized nucleosomes. Either free Htz1-H2B dimers or dimers associated with the NAP-Z complex could be transferred by the SWR1 enzyme (Fig. 4, A and $\mathrm{B}$ ), indicating that Nap1 functions as an escort rather than part of the histone transfer machinery. The reaction proceeds efficiently at room temperature with catalytic levels of the SWR1 complex (one enzyme to $\sim 50$ nucleosomes) and stoichiometric amounts of Htz1-H2B, resulting in substantial transfer of Htz1-Flag to the immobilized nucleosome array in $60 \mathrm{~min}(77 \%$ transfer of free Htz1-H2B dimers and $57 \%$ transfer of Nap1-associated dimers). Transfer of Htz1 is readily observed within 5 min (Fig. 4D) and is specific for nucleosomal templates, because none occurs on immobilized, naked DNA (fig. S2). Moreover, the SWR1 complex transfers Htz1-H2B selectively over $\mathrm{H} 2 \mathrm{~A}-\mathrm{H} 2 \mathrm{~B}$, as shown by weak transfer $(11 \%)$ when tagged $\mathrm{H} 2 \mathrm{~A}-\mathrm{H} 2 \mathrm{~B}$ dimers are substituted for tagged Htz1-H2B in an otherwise identical reaction (Fig. 4E) and by the excess of competing $\mathrm{H} 2 \mathrm{~A}-\mathrm{H} 2 \mathrm{~B}(\sim$ ninefold $)$ required to reduce transfer of tagged Htz1-H2B by half (Fig. 4F).

Although maximal incorporation of Htzl into immobilized chromatin requires exogenous ATP, we could reproducibly detect transfer in the absence of ATP (Fig. 4A, 7\%; 
Fig. 4B, 18\%). This was also observed when ATP was substituted with adenosine diphosphate, guanosine triphosphate, and nonhydrolyzable ATP analogs (Fig. 4C). Such transfer of Htzl likely results from endogenous ATP bound to the purified SWR1 complex, because transfer was not detectable when an intact enzyme complex carrying a mutation in the ATP binding site of Swr1 (fig. S3) was substituted for the wild-type complex (Fig. 4C). We also evaluated other complexes of the SWI/SNF family. At equimolar or greater levels to the SWR1 complex, purified ISW1 (imitation switch), SWI/SNF, RSC (remodel the structure of chromatin), and INO80 complexes transferred Htz1 weakly (Fig. 4G) despite having higher ATPase activities (fig. S5).

To address the fate of histone $\mathrm{H} 2 \mathrm{~A}$ in the nucleosome upon transfer of Htzl by SWR1, we analyzed the products of the transfer reaction with the use of SDS-polyacrylamide gel electrophoresis (SDS-PAGE) and silver staining (which allows preferential visualization of yeast histones $\mathrm{H} 2 \mathrm{~A}$ and $\mathrm{H} 2 \mathrm{~B}$ ). Of the four core histones, we found that only histone H2A was substantially displaced $(\sim 60 \%)$ from immobilized nucleosome arrays upon transfer of Htz1. By contrast, the level of histone $\mathrm{H} 2 \mathrm{~B}$ (and $\mathrm{H} 3$ and $\mathrm{H} 4$ ) remained essentially unchanged (Fig. 5A). Hence, we conclude that the SWR1 complex catalyzes displacement of histone $\mathrm{H} 2 \mathrm{~A}$ and replacement with Htzl in a bona fide histone exchange reaction. To verify the native conformation of nucleosome core particles produced by the histone replacement reaction, we reconstituted mononucleosomes on a 201-base pair (bp) DNA fragment with the use of bacterially expressed, conventional histone octamers. Mononucleosomes were incubated with SWR1 complex, tagged Htz1H2B dimers, and ATP, followed by digestion with micrococcal nuclease to release the nucleosome core particle. Native gel electrophoresis and DNA staining showed that the bulk of the core particle population retains native conformation, as judged by electrophoretic mobility. The incorporation of Htz1Flag in the nucleosome core particle was shown by Western blot analysis of the native gel (Fig. 5B).

Histone exchange: A distinct mechanism for chromatin remodeling. Two chromatin remodeling mechanisms involving alterations in DNA-histone contacts without major perturbation of the histone octamer have been proposed $(2,5)$. In the "sliding" mechanism, the ATP-driven propagation of a local DNA twist or bulge over the histone octamer surface, initiating from the DNA entry or exit positions, causes the octamer to be relocated relative to the DNA sequence. There is general agreement that the comparatively small $(\sim 0.5 \mathrm{MD})$ ISWI-containing
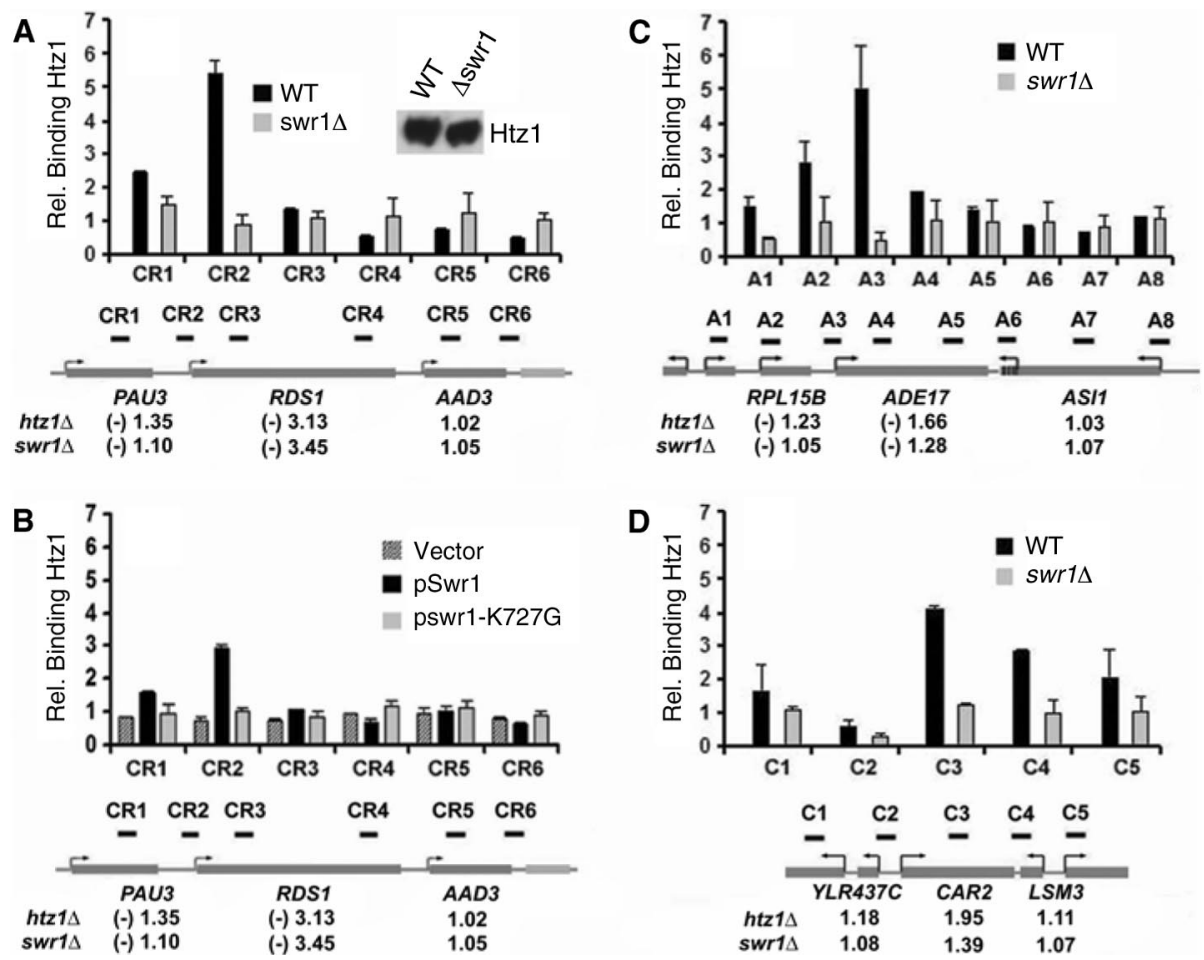

Fig. 3. Chromatin binding of Htz1 in vivo is dependent on Swr1. Bar diagrams showing in vivo binding of Htz1-Flag as measured by ChIP in the indicated strains. Immunoprecipitated DNA was analyzed by real-time polymerase chain reaction with the use of primers for (A and $\mathbf{B})$ the RDS1 locus, (C) the ADE17 locus, and (D) the CAR2 locus, as indicated by the black bars above the gene maps. Binding was measured relative to ARE1, a gene not regulated by HTZ1 or SWR1. Changes (-fold) in gene expression in $h t z 1 \Delta$ and swr1 $1 \Delta$ mutants relative to WT are included below the maps.

complexes use a sliding mechanism to shift nucleosome positions within a nucleosome array in vitro $(2,5)$. Importantly, remodeling intermediates detected in vivo are consistent with a nucleosome sliding mechanism for yeast ISW2 (27). A more complicated DNA "looping" mechanism distinguishes the large $(\sim 1 \mathrm{MD}) \mathrm{SWI} / \mathrm{SNF}$ and closely related enzymes from ISWI enzymes. The looping mechanism is characterized by peeling of a long DNA segment from one edge of the nucleosome, octamer mobilization, and DNA rewrapping (28); nucleosomal DNA is globally distorted and becomes more susceptible to restriction nuclease digestion (2). Both sliding and looping mechanisms apparently involve an ATP-dependent DNA-translocating activity displayed by Swi2/Snf2 family proteins $(2,5,29,30)$.

The catalytic exchange of nucleosomal $\mathrm{H} 2 \mathrm{~A}$ for the H2AZ variant by the SWR1 complex suggests a previously unknown mechanism of chromatin remodeling that necessitates the disruption of histone-histone as well as histone-DNA contacts. Assuming the $\mathrm{H} 2 \mathrm{~A}-\mathrm{H} 2 \mathrm{~B}$ dimer to be the unit of histone exchange, histone replacement necessitates displacement of two $\mathrm{H} 2 \mathrm{~A}-\mathrm{H} 2 \mathrm{~B}$ dimers from the nucleosome core particle. We propose that, like SWI/SNF (28), the SWR1-catalyzed unwrapping of nucleosomal DNA from the entry or exit positions of the nucleosome exposes the DNA-binding surface of an H2A$\mathrm{H} 2 \mathrm{~B}$ dimer. This unwrapping should promote the intrinsic tendency of the histone octamer to dissociate into constitutent H2A-H2B dimers and the $(\mathrm{H} 3-\mathrm{H} 4)_{2}$ tetramer $(6,31,32)$. In addition, components of the SWR1 complex could directly provoke dissociation of the first $\mathrm{H} 2 \mathrm{~A}-\mathrm{H} 2 \mathrm{~B}$ dimer from the histone octamer. Subsequent release of Htz1-H2B from the SWR1 complex near the vacant site, coupled with relaxation or rewrapping of DNA, would then reassemble a core particle containing one each of $\mathrm{H} 2 \mathrm{~A}-\mathrm{H} 2 \mathrm{~B}$ and Htz1-H2B dimers. Structural incompatibility between two heterotypic dimers within the same nucleosome core particle (12) should then facilitate SWR1-catalyzed exchange of the second H2A-H2B dimer in a cooperative fashion.

We note that other workers have independently found biochemical and genetic interactions between Swr1 and Htz1 or their mammalian orthologs (33), although to our knowledge the demonstration of SWR1-catalyzed ATP-dependent histone variant exchange in vitro is unprecedented. Furthermore, the transfer of histones per se is not exclusive to ATP-dependent chromatin remodeling enzymes (34).

Targeting of Htz1 and the SWR1 complex. The association of histones Htz1-H2B with the purified SWR1 complex suggests 
RESEAR C H ARTICLES

Fig. 4. ATP-dependent catalysis of $\mathrm{Htz} 1$ transfer. (A and B) Western blots showing transfer of Htz1-Flag. Immobilized nucleosome arrays (14 nM nucleosomes) were incubated with either NAP-Z (23 nM Htz1) (A) or free Htz1-H2B dimer (32 nM) (B), SWR1 complex (0.3 nM), and $1 \mathrm{mM}$ ATP as indicated. After washing, bound Htz1-Flag was eluted by SDS-PAGE sample buffer and analyzed by Western blotting. Free $\mathrm{Htz} 1$ is the combination of supernatant and wash fractions. In three experiments, the transfer of free Htz1$\mathrm{H} 2 \mathrm{~B}$ dimer was $85 \%, 77 \%$, and $76 \%$. (C) ATP requirements for $\mathrm{Htz} 1$ transfer. Reactions were incubated as in (B) with ATP analogs ( $1 \mathrm{mM}$ ) as indicated. " $\mathrm{m}$ " is the mutant complex carrying the K727G mutation in the ATP binding site of Swr1. Similar results were obtained when NAP-Z was used as a source of Htz1-H2B dimers (fig. S3). (D) Kinetics of Htz1 transfer. Reactions were conducted as in (A) for the indicated times. (E) Weak transfer of H2A-H2B by SWR1 (11\%) and SWI/SNF (14\%). Reactions were identical to (B), except that purified (H2A-Flag)-H2B dimers were used and SWI/SNF concentrations were fivefold higher than those of SWR1. In another set of experiments, H2A-H2B transfer by SWR 1 and SWI/SNF was $4 \%$ and $10 \%$, respectively. (F) H2A-H2B competes poorly against Htz1-H2B. Reactions were as in (B), except for inclusion of recombinant yeast histone octamers as a source, upon dissociation, of free H2A-H2B dimers. (G) Htz1 transfer is specific to SWR1. Purified remodeling complexes (equimolar to and fivefold greater than the SWR1 complex) were analyzed as in (A) for ISWI1, SWI/SNF, RSC, or as in (B) for INO80.
A

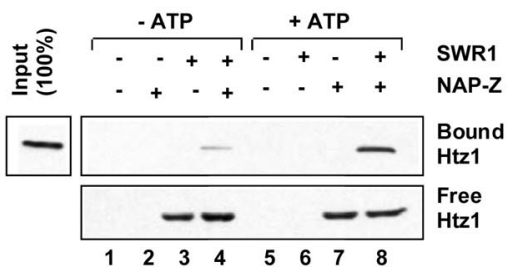

B

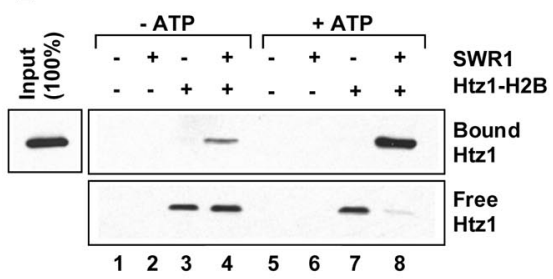

C
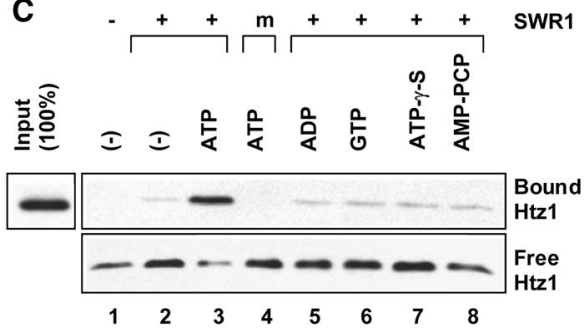

D

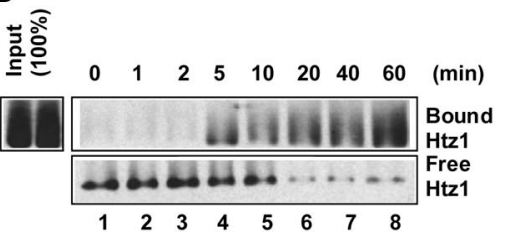

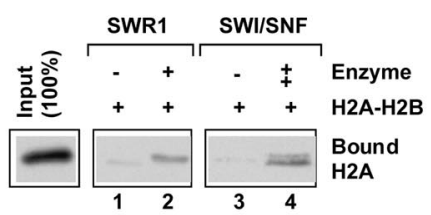

$\mathbf{F}$

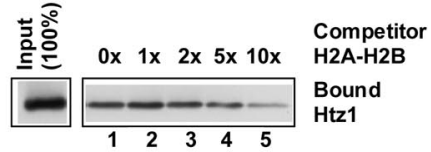

G
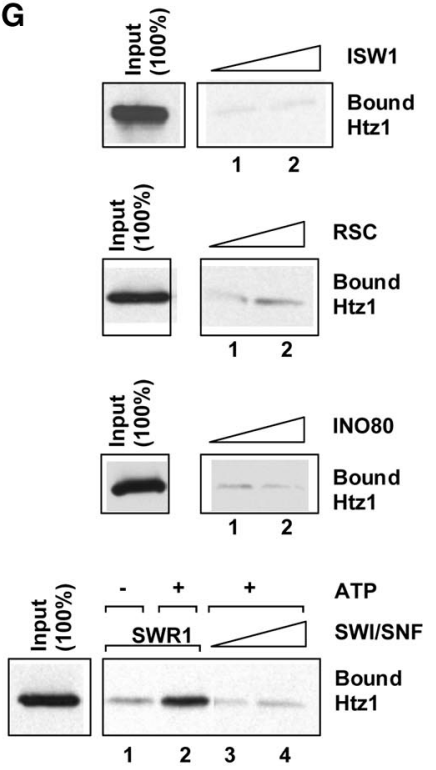

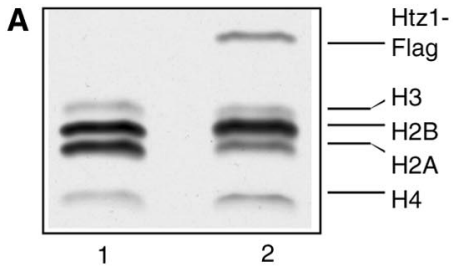

Fig. 5. SWR1 complex exchanges nucleosomal $\mathrm{H} 2 \mathrm{~A}$ with Htz1. (A) SDS-PAGE and silver staining showing histones retained on immobilized nu cleosome arrays before (lane 1) and after (lane

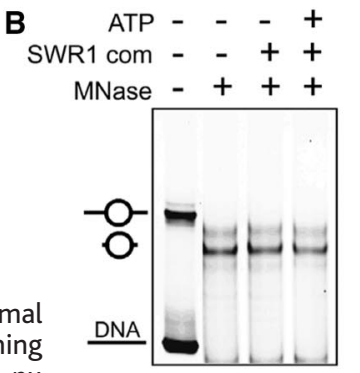

Native Gel

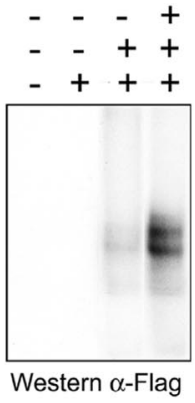

Western $\alpha$-Flag

2) $\mathrm{Htz} 1$ transfer. This reaction is a 10-fold scale-up of the one in Fig. 4B. Changes in histone $\mathrm{H} 2 \mathrm{~B}$ $(108 \%)$ and $\mathrm{H} 2 \mathrm{~A}(37 \%)$ in lane 2 compared with lane 1 were derived with the use of laser densitometry. Changes in $\mathrm{H} 3$ and $\mathrm{H} 4$ could not be quantified accurately because of poor silver staining. (B) Native PAGE and DNA staining (left) and Western blotting (right) showing nucleosome core particles before and after the $\mathrm{Htz} 1$ transfer reaction. Nucleosomes reconstituted from conventional yeast histones and a 3' biotinylated 201-bp DNA fragment were incubated with the SWR1 complex, NAP-Z, and ATP. Mononucleosomes were bound to magnetic beads, washed, and digested with micrococcal nuclease (MNase), and the released core particles were analyzed by native PAGE $(0.5 \times$ tris-borate EDTA). The gel was analyzed by Western blotting to detect Htz1-Flag. (A digestion intermediate migrates between the nucleosome and the core particle in both native gel and Western blot.)

that specific SWR1 components are responsible for binding to Htzl. Likely candidates are the actin-related proteins (Arps), some of which have a role in the chromatin remodeling process and exhibit histone-binding activity in vitro $(16,35-37)$. The SWR1 complex contains actin, Arp4, and, uniquely, Arp6, raising the prospect that Arp6 may have a key role in sequestering the Htz1-H2B dimer specifically.

The SWR1-dependent incorporation of Htzl at either intergenic or transcribed re- gions suggests that enzyme recruitment to chromatin may involve more than promoter-specific factors and raises the possibility that Htzl affects both initiation and elongation stages of transcription. Indeed, recent genetic studies underscore a role for Htz1 in transcription elongation (38). The additional Htzl-interacting proteins we have identified by mass spectrometry could contribute toward this function. How the presence of one or several Htzl-variant nucleosomes within a conventional nucleosome array affects transcription initiation or elongation is unclear.

Implications for chromatin remodeling enzymes. The catalysis of $\mathrm{H} 2 \mathrm{AZ}$ variant exchange by the SWR1 complex invites speculation on a general mechanism by which histone variants are incorporated into nucleosomes (9). We suggest that other ATPdependent chromatin remodeling complexes $(2,5,14)$ might catalyze the incorporation of specific histone variants (39), although proteins such as chromatin assembly factors may also be important (9). Moreover, covalent modifications might provide histone signals for the catalytic exchange of histone variants or even of major histones, thereby contributing to mechanisms for hi- 
stone replacement and nucleosome loss associated with transcription in vivo $(9,40$, 41). The further development of assays to capture the movements of physiologically marked histones should provide insight into the regulation of chromatin dynamics.

Note added in proof: The subunits of the SWR1 complex-Vps72, Swc1, God1, Aor1, and Vps71-have been renamed Swc2, Swc3, Swc4, Swc5, and Swc6, respectively, by agreement with the laboratories of $\mathrm{J}$. Greenblatt, H. Madhani, and J. Rine.

References and Notes

1. R. D. Kornberg, Y. Lorch, Cell 98, 285 (1999).

2. G. J. Narlikar, H. Y. Fan, R. E. Kingston, Cell 108, 475 (2002).

3. W. Fischle, Y. Wang, C. D. Allis, Curr. Opin. Cell Biol. 15, 172 (2003).

4. J. A. Martens, F. Winston, Curr. Opin. Genet. Dev. 13 136 (2003).

5. P. B. Becker, W. Horz, Annu. Rev. Biochem. 71, 247 (2002).

6. K. E. Van Holde, Chromatin (Springer-Verlag, New York, 1989)

7. C. Redon et al., Curr. Opin. Genet. Dev. 12, 162 (2002).

8. M. M. Smith, Curr. Opin. Cell Biol. 14, 279 (2002).

9. K. Ahmad, S. Henikoff, Proc. Natl. Acad. Sci. U.S.A. 99 (suppl. 4), 16477 (2002)

10. M. J. Clarkson, J. R. E. Wells, F. Gibson, R. Saint, D. J. Tremethick, Nature 399, 694 (1999).

11. C. L. Hatch, W. M. Bonner, E. N. Moudrianakis, Science 221, 468 (1983).

12. R. K. Suto, M. J. Clarkson, D. J. Tremethick, K. Luger, Nat. Struct. Biol. 7, 1121 (2000).
13. M. D. Meneghini, M. Wu, H. D. Madhani, Cell 112, 725 (2003).

14. I. A. Olave, S. L. Reck-Peterson, G. R. Crabtree, Annu. Rev. Biochem. 71, 755 (2002).

15. X. Shen, G. Mizuguchi, A. Hamiche, C. Wu, Nature 406, 541 (2000).

16. X. Shen, R. Ranallo, E. Choi, C. Wu, Mol. Cell 12, 147 (2003).

17. More information is available online at www. yeastgenome.org.

18. Materials and methods are available as supporting material on Science Online.

19. G. Mizuguchi et al., unpublished observations.

20. H. V. Goodson, W. F. Hawse, J. Cell Sci. 115, 2619 (2002).

21. P. M. Ayton, M. L. Cleary, Oncogene 20, 5695 (2001)

22. Y. Ishimi, A. Kikuchi, J. Biol. Chem. 266, 7025 (1991).

23. M. Hampsey, Yeast 13, 1099 (1997).

24. T. J. Begley, A. S. Rosenbach, T. Ideker, L. D. Samson, Mol. Cancer Res. 1, 103 (2002).

25. M. E. Gelbart, T. Rechsteiner, T. J. Richmond, T. Tsukiyama, Mol. Cell. Biol. 21, 2098 (2001).

26. K. Luger, T. J. Rechsteiner, T. J. Richmond, Methods Enzymol. 304, 3 (1999)

27. T. Fazzio, T. Tsukiyama, Mol. Cell 12, 1333 (2003).

28. S. R. Kassabov, B. Zhang, J. Persinger, B. Bartholomew, Mol. Cell 11, 391 (2003).

29. A. Saha, J. Wittmeyer, B. R. Cairns, Genes Dev. 16, 2120 (2002).

30. I. Whitehouse, C. Stockdale, A. Flaus, M. D. Szczelkun, T. Owen-Hughes, Mol. Cell. Biol. 23, 1935 (2003).

31. K. E. Van Holde, J. Zlatanova, G. Arents, E. Moudrianakis, Chromatin Structure and Gene Expression (Oxford Univ. Press, ed. 1, 1995).

32. T. J. Richmond, J. Widom, Chromatin Structure and Gene Expression (Oxford Univ. Press. ed. 2, 2000).

33. Y. Nakatani, J. Rine, J. Greenblatt, personal communication.

34. As an example, stoichiometric binding of FACT (facilitates chromatin transcription) assists displacement of $\mathrm{H} 2 \mathrm{~A}-\mathrm{H} 2 \mathrm{~B}$ dimers (42).
35. M. Harata et al., Mol. Biol. Cell 10, 2595 (1999) 36. L. Galarneau et al., Mol. Cell 5, 927 (2000).

37. H. Szerlong, A. Saha, B. R. Cairns, EMBO J. 22, 3175 (2003).

38. M. M. Smith, personal communication.

39. The RSC complex is required (apparently indirectly) for deposition of the centromere-specific histone variant Cse4 (43)

40. H. Boeger, J. Griesenbeck, J. S. Strattan, R. D. Kornberg, Mol. Cell 11, 1587 (2003).

41. H. Reinke, W. Horz, Mol. Cell 11, 1599 (2003).

42. M. Belotserkovskaya et al., Science 301, 1090 (2003).

43. J. M. Hsu, J. Huang, P. B. Meluh, B. C. Laurent, Mol. Cell Biol. 23, 3202 (2003).

44. Data is available at http://home.ccr.cancer.gov/ landrydata803/.

45. We thank Y. Natakani and $\mathrm{H}$. Tagami for stimulating discussions; T. Tsukiyama, K. Luger, M. Lichten, and members of their laboratories for reagents, histone protocols, and advice; J. Delrow for advice on microarray analysis; W. Lane for protein microsequencing; T. Tsukiyama, J. Palmer, and R. Ranallo for initial studies; J. Widom for a nucleosome positioning sequence; and Y. Nakatani, J. Rine, M. Smith, T. Tsukiyama, J. Greenblatt, J. Cote, and P. Silver for communicating unpublished results. This work was supported by the National Cancer Institute.

Supporting Online Material

www.sciencemag.org/cgi/content/full/1090701/DC1

Materials and Methods

Figs. S1 to S5

Tables S1 to S3

References

22 August 2003; accepted 11 November 2003

Published online 27 November 2003;

10.1126/science. 1090701

Include this information when citing this paper.

\section{Self-Assembly of Mesoscopic Metal-Polymer Amphiphiles}

\author{
Sungho Park, Jung-Hyurk Lim, Sung-Wook Chung, Chad A. Mirkin*
}

The assembly properties of two- and three-component rod-like building blocks consisting of gold and polymer block domains have been investigated. These structures behave like mesoscopic amphiphiles and form a series of single-layer superstructures consisting of bundles, tubes, and sheets depending upon the compositional periodicity. Unlike molecular systems, the template used to initially synthesize them plays a critical role in the assembly process by prealigning them in a manner that facilitates their assembly by optimizing the correct collisional orientation upon dissolution of the template. Tubular structures with tailorable diameters can be assembled in a predictable manner on the basis of an estimate of the hybrid rod packing parameters.

Over the past decade, major advances have been made in the synthesis and characterization of one-dimensional rod-like nanostructures (1). One can now synthesize, via a

Department of Chemistry and Institute for Nanotechnology, Northwestern University, 2145 Sheridan Road, Evanston, IL 60208-3113, USA.

*To whom correspondence should be addressed. Email: camirkin@chem.northwestern.edu variety of routes, carbon-based nanotubes, polymer structures, and metal, semiconducting, and insulator inorganic compositions (28 ). These materials have several unusual and potentially useful properties that make them promising for many potential applications in optics (9), electronics (10), and biodiagnostics (6). One of the most powerful and now extensively used methods for synthesizing such structures relies on solid-state templates and electrochemistry to control the diameter and length of such structures $(6,11)$. Using this approach, one can synthesize one- and multicomponent structures with exquisite control over block composition size. Although these rod-like building blocks can be routinely made in large quantities and in massively parallel fashion, only a few techniques allow one to assemble them into organized two- and three-dimensional structures (1217). No techniques have been developed for controlling their assembly into curved structures, a capability necessary to fully understand and exploit the concept of self-assembly with unnatural mesoscopic building blocks (18).

Our approach to generating mesoscopic amphiphiles involves the synthesis of rodlike structures consisting of hard and soft domains. The hard hydrophilic domain is an inorganic material such as gold, and the soft domain is a hydrophobic conducting polymer such as oxidized polypyrrole, which can be electrochemically polymerized within the confines of an alumina template. The rationale was that because of the compositional differences between the inorganic and organic portions of these novel structures, the 